\title{
PODER, TRADUCCIÓ, POLÍTICA ${ }^{1}$
}

\section{FRANCESC PARCERISAS}

Senyores $i$ senyors, distingits col-legues $i$ amics,

En primer lloc em permetran que agraeixi l'amable invitació del Dept. d'Espanyol i Portuguès a participar en aquest colloqui anual a Bloomington i en especial al nostre hoste, Josep Miquel Sobrer, la seva hospitalitat i la llarguíssima amistat amb què m'honora d'ençà que vam coincidir, ja fa prop de quaranta anys, a les aules grises però en plena ebullició intel-lectual i política de la Facultat de Filosofia i Lletres de la Universitat de Barcelona.

Sóc aquí, entre catalanòfils d'Amèrica, per parlar d'una activitat que per a nosaltres és òbvia: la traducció. Una activitat sense la qual la relació entre la cultura catalana i la cultura americana fóra debades, perfectament inútil. La traducció té, en aquest sentit, la virtut de ser una activitat sovint mig ignorada, una activitat que no té, de cara al públic, la visibilitat "agent" d'altres empreses culturals. Però val a dir que aquest segon pla en què la traducció es mou li permet de poder manifestar formes de la implicació ideològica dels centres de poder en el sistema cultural que altres accions més vistents s'ocupen d'emmascarar amb una més gran diligència.

No els parlaré, doncs, de l'interès filològic que, per descomptat, té la traducció en les seves diverses facetes, sinó d'aquells altres elements de tipus social i cultural que podem esbrinar gràcies a l'activitat traductora i que projecten molta llum sobre l'ordit del sistema cultural en què ens movem. Els en parlaré d'una manera potser un xic anecdòtica tot i que, d'entrada, m'agradaria posar algunes cartes tan importants com elementals damunt la taula.

La traducció com a element imprescindible en les relacions interlingüístiques $\mathrm{i}$ interculturals, com a element, per tant, imprescindible

I La idea original d'aquest article va ser escrita com un article periodístic en castellà per al diari El Pais. Tot i que no va ser mai publicada, després va aparèixer, traduïda anònimament al catală (segurament per Pau Vídal, de la redacció barcelonina del mateix diari) al "Quadern de Cultura", el suplement cultural de l'edició barcelonina dels dijous (13 novembre 1997, p. 3). És d'una ironia que sembla deliberada que la versió caralana no mencionés el nom del traductor de l'article, que era allò que el text justament denunciava.

He fet servir els mateixos exemples per a una comunicació presentada al IV Congrés Internacional sobre Traducció del Departament de Traducció i d'Interpretació de la Universitat Autònoma de Barcelona, maig 1998. El text és pràcticament el mateix de la mevs lliçó inaugural del curs $1998-99$ a la Facultat de Traducció de la Universitat Pompeu Fabra de Barcelona a loctubre de 1998. 
en el món actual, manté un lligam molt estret amb allò que de vegades denominem els sistemes de poder $i$ amb les maneres com aquests sistemes de poder actuen, és a dir, amb les seves polítiques. La traducció és, en aquest sentit, una disciplina que ens pot servir per veure accentuada o esborrada la diferència entre sistemes de pensament, o literaris, tant si són veïns com molt allunyats, per fer-nos adonar de les relacions desiguals entre cultures o de la tendència a l'homogeneïtzació interessada. De seguida ho veurem.

El primer exemple que m'agradaria posar és ben recent i demostra com el concepte de traducció pot ser aplicat en sentits perfectament divergents $\mathrm{i}$ aplicat a gairebé tots els fets que constitueixen la vida pública. Fa encara no una setmana, el diumenge 27 de febrer de 2000 , la premsa de Barcelona informava que la comissió per als Drets Humans del Departament d'Estat Nord-americà acabava de publicar el seu informe anual sobre l'estat dels drets humans arreu del món. Segons aquestes informacions, ${ }^{2}$ la publicació contenia algunes referències a Catalunya, probablement extretes de la premsa espanyola i dels serveis d'informació de les ambaixades i consolats. Aquestes informacions criticaven les quotes de català a la ràdio i la televisió, una suposada imposició lingüística a l'ensenyament $i$ diverses actuacions del Govern català relacionades amb la seva política lingüística. Per a mi, l'interès d'aquest informe - a més de mostrar la perspectiva d'un poderós agent de la política mundial-radicava en el fet que un parell de dies abans, en un altre diari de Barcelona, ${ }^{3}$ havia llegit una carta al director, que s'expressava en termes radicalment oposats. Els llegeixo íntegre el text d'aquella carta que cal entendre en el context de les pròximes eleccions estatals espanyoles:

"Que el Sr. Almunia [el candidat del Partit Socialista espanyol a la presidencia del govern] digui que la política lingüistica a Catalunya és un problema (per als castellanoparlants) es pot entendre des d'una òptica roïna i per interessos electoralistes en clau espanyola. Que els senyors Serra i Maragall [els representants del Partit dels Socialistes de Catalunya] facin el paperot de PSC i diguin que a Catalunya no hi ha cap problema lingǘstic (contradient el seu amo), també s'entén pels seus interessos de cara a la Generalitat.

Allò que no entenc és que els senyors Pujol i Puigcercós [el president de Convergència $i$ Unió $i$ el candidat d'Esquerra Republicana] també diguin que a Catalunya no hi ha problema lingüístic. Què volen

2 Vegeu El Pais, edición Cataluña, 27 de febrero de 2000, p. I i 4 de la secció Cataluña. La notícia va signada per Manel Torres.

3 Avui, divendres 25 de febrer de 2000, p. 4 . 
dir? Deu ser per als castellanoparlants, perquè per als catalanoparlants sí que n'hi ha, de problema, i n'hi ha cada dia de l'any, perquè a les universitats es fan cada vegada més classes en castellà; perquê a les comissaries es parla en castellà; perquè si vas al notari li has de dir ben clar que els documents no els vols en castellà; perquè si vas al cinema estàs condemnat a sentir la pel-lícula en castellà; perquè el guàrdia urbà només parla en castellà; perquè la carta del restaurant està escrita en castellà; perquè a TV $i$ als mitjans de comunicació en general la proporció catalàcastellà és vergonyosa; perquè els meus fills (molt petits ara) qualsevol dia s'adonaran que la llengua normal a Catalunya és el castellâ...

Senyors Pujol i Puigcercós, per descomptat que hi ha problema lingüistic a Catalunya, i greu. Perquè la veritat és que en aquest país no es pot viure en català i, si això no ho veuen, no sé perquè volem l'autonomia".

Allò que m'interessa d'aquestes dues posicions antagòniques respecte a la possibilitat de "viure en català", és que parteixen de pressupòsits diferents respecte a quin és l'"original" de la vida a Catalunya i quina és la seva "traducció". Al Departament d'Estat Nord-americà li sembla prou bo d'identificar la llengua hegemònica de l'Estat espanyol i les possibles traduccions de les llengües més petites a la llengua "imperial" ficant-ho tot dins un sol paquet. L'original "imperial" té força i prestigi suficient per fagocitar i anorrear els altres "originals" més petits. La traducció segurament és bona, possible i necessària, encara que esdevingui un mitjà de genocidi lingüístic. Per al senyor Josep Maria Montserrat i Trens, que és qui signa la carta a l'AVUI, l'únic original possible és el català i tota traducció representa una pèrdua de poder i, per tant, un afebliment del sistema cultural i lingüístic amb el qual ell se sent identificat. Això que veiem aquí tan ben exemplificat en termes de domini polític no és gens diferent del que trobem cada dia en l'àmbit de la traducció estrictament literària o periodística.

No sé si són molts els lectors de premsa o de llibres impresos que tenen el mateix costum que tinc jo, però el cert és que considero molt gratificant de poder localitzar a l'encapçalament $\mathrm{o}$ al peu d'una notícia, o a la pàgina de crèdits d'un llibre, o també al peu d'una foto o d'un dibuix o d'un cartell que m'hagin cridat l'atenció, el nom del seu autor. Un dels trencaclosques menys gratificants de la història de les traduccions és no trobar cap mena d'indicació sobre qui en va ser el responsable, qui l'editor o quin any van ser editades. Tanmateix, d'ençà dels anys seixanta i sobretot en els últims deu o quinze anys -i gràcies en gran part a les pressions de les associacions professionals, a la llei de la propietat intel-lectual espanyola $i$ al reconeixement generalitzat que cal dignificar el treball de tots els intermediaris en el procés de producció de la comunicació artística $\mathrm{i}$ intel-lectual-, la pràctica del reconeixement de l'autoria ha esdevingut, per sort, força comuna. 
Sembla just, en efecte, que existeixi un reconeixement del treball individual dels creadors $\mathrm{i}$ de tots aquells que subsidiàriament intervenen en el procés creador. De fet, en una societat com la nostra, tan atenta sobretot a la legitimació d'allò que és comercial, d'allò que és estrictament $i$ literalment moneda de canvi - $i$ en conseqúència producte que possibilita un guany econòmic (una reificació del treball en capital, que hauria dit Marx) -, és d'agrair que l'autoria dels béns intel-lectuals $i$ artístics no hagi quedat totalment relegada al guany de qui especula amb el treball d'altri ${ }^{4} \mathrm{i}$, si més no de tant en tant, esdevingui també una activitat de prestigi social i econòmic, $i$ una relació de causa-efecte en el consum cultural que el públic accepta de bon grat $i$, fins i tot, de vegades demana. Pensin en una indústria econòmicament tan poderosa com la cinematogràfica i com els electricistes, càmeres, ajudants de vestuari, maquilladores, perruqueres i dobles solen veure's recompensats públicament en el reconeixement de la seva feina en aparèixer el seus noms a la llista dels crèdits cinematogràfics.

El món de la traducció tampoc no és del tot aliè a aquest fenomen, tot i que encara s'hi presenta de forma escadussera i, sovint sota aspectes gairebé vergonyants, però, de tant en tant, existeixen casos excepcionals i dins la literatura catalana moderna ens és llegut de parlar de l'Odissea DE Riba, de la Divina Comèdia DE Sagarra, del Pigmalió DE Joan Oliver, dels poemes xinesos DE Marià Manent, de l'Ulisses DE Mallafrè, del Shakespeare DE Salvador Oliva o de Les mil $i$ una nits DE Dolors Cinca i Margarida Castells... Reconeixem, d'aquesta manera, que, sense els traductors no hauríem tingut accés -o no hauríem tingut un accés tan notable- a l'obra en qüestió. I equiparem l'autoria de l'original a l'autoria de la traducció. El traductor esdevé quelcom més que intermediari per fer-se corresponsable, de ple dret - com, altrament, caldria esperar sempre-, de la versió en la llengua d'arribada. L'habitual invisibilitat del traductor s'ha fet una mica més tangible $\mathrm{i}$, en alguns d'aquests casos, podríem parlar fins i tot de culminació d'aquesta màxima aspiració de la competència traductora que és la "visible invisibilitat".

Parem-nos un moment a examinar alguns d'aquests casos per les conseqüències que em sembla que tenen en l'actitud amb què el públic lector rep determinades traduccions. A l'extrem contrari del cas d'un escriptor famós que garanteix amb el seu nom la bondat de les traduccions que produeix (i per exemple aquí, als Estats Units, gairebé totes

4 No ho ha quedat del tot, però encara sovint tenim mostres d'aquesta actitud arcaica i prepotent. En va ser un trist exemple l'aparició d'una collecció de quiosc de poesia en català, una sèrie d'antologies "dels millors poemes", editada per Columna i Proa, sense l'autorització dels autors o dels seus hereus. (Vegeu Avui v 498 p. 40 i la polèmica en dies posteriors.) 
les traduccions de poesia funcionen a partir del prestigi del traductor), trobem que, a la premsa, per exemple, sovintegen els articles traduits que no sols no fan menció dels traductors, sinó que ni tan sols no indiquen que es tracta de traduccions. En aquests casos podem fer dues suposicions: d'una banda que el diari creu que no cal informar els seus lectors que el text que llegeixen no és el text original, sinó una traducció $i$, d'una altra, que no cal informar de qui és el responsable de la traducció. Al darrere de totes dues actituds hi ha una dosi notable de desídia, però, també, una dosi notable d'alienació intel-lectual. M'explicaré. No es tracta del fet que el lector espanyol pugui creure que escriptors com Edward Said, Alan Gründ, Tahar Ben Jelloun o Arundhati Roy saben tan bé l'espanyol que fan servir aquesta llengua per escriure-hi directament les seves collaboracions periodístiques, o que el "do de llengües" sigui una virtut que es pressuposi de qualsevol intel-lectual estranger, de la mateixa manera com abans es predicava el "valor" de qualsevol soldat de l'exèrcit. Allò que preocupa no és la possible innocència del gran públic, sinó, més aviat, que sembla existir una acceptació implícita sobre el fet que original i traducció són del tot idèntics. No cal dir com en els terrenys ideològics, polítics, culturals, religiosos i lingüístics, que són els que solen expressar-se a través dels articles d'opinió dels diaris, això és del tot relatiu. ${ }^{5}$ ¿ De debò no ens importa i no pot tenir cap significació que Edward Said escrivís el seu article en àrab o en anglès, que Tahar Ben Jelloun ho fes en francès i que Arundhati Roy escrigui en anglès o en mayamalam? ¿És que amb el postulat implícit de la universalitat de les idees l'argument subliminal que el diari ens vol vendre és que la seva orientació és també "universal" $i$, en aquest sentit, "indiscutible", mai no distorsionada per l'obligada traducció? ¿Per ventura si haguéssim sabut que l'article era traduït, $i$ traduit d'una llengua determinada, l'hauriem llegit de manera diferent? Em limito a deixar oberts aquests interrogants.

Permetin-me d'afegir un segon exemple desconcertant. En una sèrie de magnífiques entrevistes antigues, titulada "Lectura. I50 años de entrevistas", publicades durant moltes setmanes de 1997 al suplement setmanal del diari El País, ${ }^{6}$ vaig comprovar el mateix fet. Tot i que l'en-

5 SAID, Edward, "La campaña contra el 'terror islámico", El Pais, is d'abril de 1996 , p. 13. Grúnd, Alain, "El precio fijo a único de los libros", El País, is de setembre de 1997. p. 40; BEN JElloun, Tahar, "El Mundial me saca de quicio", El Pais, ro de juny de 1998, p. I6; RoY, Arundhati, "EI final de la imaginación", El Pais Domingo, año XIV, n" 668, 2 d'agost de 1998 , p. 1-5.

6 L'entrevista amb Oscar Wilde va ser publicada originàriament a la St. James Gazette el 18 de gener de 1895 (El País Semanal n 1060, 19 de gener de 1997, p. 81-83 traduida per Antonio Resines i Herminia Bevia). L'entrevista amb Tolstoi va ser publicada a The Manchester Guardian el 9 de febrer de 1905 (El País Semanal estiu de 1997, no en tinc la data exacta). L'entrevista amb Hemingway prové d'Argosy, setembre 
trevista amb Oscar Wilde, apareguda originàriament l'any 1895 , constava que l'havien traduïda Antonio Resines i Herminia Bevia, ni la de Samuel Beckett, ni la d'Ernest Hemingway, ni la de Lleó 'Tolstoi no duien nom de traductor. Vagin a saber si l'estrany bilingüisme de Beckett en podia haver justificat la desaparició, o si el pobre espanyol de Hemingway potser també podria haver-ne estat una mala excusa, però vaig haver de malpensar i qüestionar-me si en l'entrevista amb Tolstoi el traductor no havia quedat esborrat del mapa precisament perquè l'entrevista es subtitulava "el conde nihilista", llevat, no cal dirho, que l'entrevista es publiqués a The Manchester Guardian de 1905 en castellà, la qual cosa hauria estat una heroïcitat més de les moltes que, en vida, va protagonitzar el gran novel-lista rus.

Poso aquests exemples per demostrar com el traductor, encara que sempre existeixi, i de vegades fins i tot envoltat d'una certa aurèola de prestigi, molt més sovint és considerat participant prescindible quan no un simple mal necessari. En cap cas, però, els responsables d'aquests escamotejos no semblen adonar-se de la importància absoluta que, més enllà de la visibilitat traductora, els actes de traducció comporten. ¿Va dir Tolstoi realment allò que The Manchester Guardian reproduïa en anglès; i el que deia The Manchester Guardian és allò que nosaltres hem llegit a El Pais Semanal? ¿Les paraules russes de Tolstoi pronunciades fa un segle encara tenen el mateix sentit? De cap de les maneres no ho dic amb la idea que el traductor pugui haver introduït elements pertorbadors que distorsionin el missatge original. Molt al contrari; ho dic perquè sense aquesta intervenció activa i deliberada del traductor, el missatge original, la cultura original, de cap de les maneres no hauria arribat amb la integritat que sempre desitgem al públic receptor o no hauria estat capaç de resistir aquest salt a través del temps. Els en posaré un altre exemple, que m'hauran de disculpar perquè té un contingut no sols políticament molt incorrecte sinó francament obscè. En qualsevol cas veuran que va molt bé per exemplificar a què faig referència.

Hi ha casos en què gràcies a les informacions addicionals que forneix el mateix text ens adonem de fins a quin punt la mà del traductor - tot i que invisible, com la del bon tramoista - pot arribar a ser un lignum crucis miraculós, pot arribar a resoldre i donar sentit a situacions o locucions que, altrament, no tindrien cap mena de sentit dins la cultura d'arribada. L'escriptor i traductor Vicente Molina Foix, en una entrevista periodística amb el cantant pop anglès Elton John, feia referència als càntics obscens que els aficionats futbolístics anglesos

de 1958 (El Pais Semanal $\mathrm{n}^{\circ}$ I095, 2i de setembre de i997). La de Samuel Beckett també va aparèxer a El País Semanal de 1997, algunes setmanes més tard, havia estat publicada originalment a The New York Times, 6 de maig de 1956. 
dirigien al cantant, conegut per la seva homosexualitat, quan apareixia a la tribuna del club de futbol anglès que finançava. Sabent que la capacitat idiomàtica dels booligans anglesos per la llengua de Cervantes és més aviat reduïda i que la seva facilitat per improvisar coplillas rimades i mètricament escandides ha de vorejar el zero absolut, la feina de Vicente Molina Foix, en atribuir-los aquests tan notables com obcens rodolins, és del tot encomiable. Vociferaven els booligans anglesos a l'article en qüestió: "Alirón, alirón, alirón, Elton John es maricón" o "Que nadie se siente / si Elton está presente / o tendrás en el culo/ una polla caliente".7

No cal dir que enlloc es menciona que Vicente Molina Foix hagi estat el traductor de l'entrevista, però ho donem per suposat. Donem per suposat que ha conduit el diàleg amb Elton John en anglès $i$ que després l'ha traduitt al castellà $i$ que ha fet el mateix amb els càntics obscens dels hooligans, càntics que ha traduitt $i$ modificat perquè rimessin en castellà, mantenint la mateixa descarada grolleria de l'original. Donem per suposat, doncs, que en molts casos la invisibilitat del traductor és més aviat una mena de consens sobre l'existència d'un genial tramoista amagat. I si el seu nom no apareix enlloc és per culpa de la prepotència dels mitjans de comunicació i per la manca de força reivindicativa del col-lectiu laboral dels traductors, tot $i$ que aquesta situació no pot constituir cap sorpresa per a qui estigui acostumat a llegir com interactuen aquests camps de forces culturals. En certa manera donem per suposat que als grans mitjans de comunicació la figura del traductor només interessa en tant que productor assalariat, eficaç i ràpid, d'un producte imprescindible, però no en tant que autor d'una feina que cal reconèixer intel-lectualment $\mathrm{i}$ explícita. De la mateixa manera com ens cal reconèixer amb humilitat que sovint, des del camp de la reivindicació laboral, si la remuneració és generosa i puntual, la justa visibilitat traductora podrà passar prou bé a un segon terme. En un altre moment vaig fer servir la comparança de la visibilitat del traductor amb la visibilitat de l'àngel de la guarda. Amb l'àngel donem per suposat que sempre vetlla, amatent, per nosaltres com el traductor invisible vetlla, sacrificat, pels textos traduïts, però només el recordem a les nostres oracions quan un precipici horrible i pregon és a punt d'engolir-nos.

Jo diria que, fins aquí, allò que hem vist no són més que petites oscil-lacions en la balança del poder. Hem vist com el consens universal sobre la necessitat de la traducció queda sovint ocult darrere la cortina del teatre poderós dels mitjans de comunicació, o dels autors de 
manuals d'ús, o dels fulletons turístics, o fins i tot d'alguns llibres, que no consideren necessari haver de donar tantes explicacions al públic (per bé que tampoc no solen responsabilitzar-se dels possibles errors). Ara bé, el problema més greu es produeix quan, en un món agnòstic com el nostre, la figura de l'àngel de la guarda i la del traductor han deixat de ser presències tàcites $\mathrm{i}$ han desaparegut del tot. Aleshores, descreguts com som, donem per suposat que només existeix allò que és visible, i que darrere la cortina del text ja no hi ha cap mà oculta, que cap traductor tramoista no guia les passes de la nostra lectura. En aquests casos la traducció sembla haver desaparegut del tot, anorreada. Ha deixat de ser in-visible, és a dir, una negació de la visibilitat, per, de manera pura i rasa, simplement no ser. I és quan ens trobem amb aquestes situacions que podem suposar que existeix tot un sistema cultural que té un interès particular per no admetre la possibilitat de la diferència traductora, ni que sigui per menystenir-la. És a dir, la balança del poder s'inclina per una línia d'actuació determinada, per una opció política concreta. Els en dono un parell d'exemples.

El dia ro d'agost de 1997 vaig veure publicat, dins una sèrie de lectures estiuenques d'escriptors "espanyols" joves, el relat "Vacaciones" de l'escriptor Quim Monzó. De seguida em va sorprendre que el relat fos escrit directament en castellà. De fet, el diari on apareixia no deia enlloc que Quim Monzó l'hagués escrit en castellà, però tampoc no deia que fos un escriptor que escriu en català, i tampoc no mencionava que el relat fos una traducció. ${ }^{8} \mathrm{~A}$ diferència dels hooligans anglesos a qui pressuposem una llengua determinada, en aquest cas el lector incaut no tenia perquè qüestionar-se la llengua de l'original com una llengua diferent d'aquella en què ell el llegia. I el lector menys incaut davant aquests temes no podia saber si es tractava d'un autor en llengua castellana, o d'un autor en llengua catalana que havia estat traduït, o d'un autor en llengua catalana que s'havia autotraduit - fenòmen que hauria estat força interessant-, o si, de fet, Monzó havia escrit deliberadament el seu relat en un català tan light que semblava ser escrit en castellà una mica encarcarat d'una punta a l'altra del text i si això ho havia fet simplement per incordiar els catalans que l'acusen de no ser suficientment light o per incordiar els castellans que diuen no entendre-li prou el seu sentit català de l'humor.'

El pobre Monzó, mancat de l’àngel de la guarda explícit del traductor, havia esdevingut alhora àngel i dimoni d'un text de procedèn-

8. Monzó, Quim, "Vacaciones", El País Semanal n ro89, io agosto r997, p. 82-86.

9. Quim Monzó va traduir a l'espanyol el seu text en català. (Q. Monzó a F. Parcerisas, 2-ivig7). El relat és publicat ara, amb el títol "Vacances d'estiu", al volum El millor dels mons, Barcelona, Quaderns Crema, 200I, p. 35 iss. 
cia ambigua. Per acabar-ho d'adobar, l'única informació complementària que el diari fornia era una mena de petita nota biografica que es limitava a dir: "Guadalajara, su última novela, ha vendido 50.000 ejemplares". Informació que feia impossible saber si Guadalajara era escrita en castellà o en català, i si les vendes eren d'una sola edició o d'ambdues.

Després $m$ 'he preocupat de buscar informació sobre aquesta sèrie de relats estiuencs $i$ he vist que, a la presentació general del que anaven a publicar, el diari menciona que dos dels participants, Manuel Rivas i Bernardo Atxaga, han rebut premis per les seves novel-les escrites en gallec $i$ en eusquera. El seu àngel, com a mínim, va ensenyar una punteta de les ales.

El problema en aquests casos no és el fet de no mencionar el nom del traductor, és no dir que el text és traduït. Sobretor si tenim en compte que res no indica, dins el propi text, que hagi de ser una traducció. Més aviat, per al mateix lector incaut de fa un moment, tot indica que es tracta de textos sense cap marca de diferència, escrits originàriament en castellà, ja que res no n'indica el contrari. I fins diria que el fet de dubtar d'aquesta premissa d'homogeneitat absoluta — com faig jo mateix ara - sembla pressuposar una certa mala fe per part de l'analista en lloc de ratificar una ideologia clarament uniformitzadora i colonialista per part d'aquells que n'han silenciat la diferència.

El fenomen no és nou. Fa sis anys, en obrir una antologia sobre la nova narrativa espanyola preparada per Juan Antonio Masoliver Ródenas, The Origins of Desire. Modern Spanish Short Stories, ${ }^{10} \mathrm{i}$ destinada al gran públic anglès, hi vaig poder observar una homogeneïtat similar. Es com si el camp de la distribució cultural, dels llibres de ficció, hagués de minimitzar qualsevol aspror que n'afectí la circulació fluida. I una de les primeres dificultats llimades és, no cal dir-ho -i sobretot davant el públic anglès de trajectòria tan poc procliu a tot allò que és ultramarí-, la diversitat de les llengües i la necessitat de la traducció. Al llibre en qüestió, s'hi publiquen contes de 29 "Spanish authors". A la introducció, que fa un breu repàs al conte com a gènere i a l'evolució de la narrativa curta a Espanya, només hi ha una menció a les diferents llengües en què escriuen els autors inclosos a l'antologia, que diu: "not all the languages in the Spanish national territory are represented in the same proportion". " $\mathrm{Ni}$ tan sols no s'indiquen quines són aquestes llengües o quins els autors. Els autors que habitualment escriuen en llengües que no són el castellà en aquesta antologia

10 Masoliver Rónenas, Juan Antonio (ed.), The Origins of Desire. Modem Spanish Short Stories, London, Serpent's Tail 1993.

if Ibid., p. 9. 
són: Robert Saladrigas, Carme Riera, Quim Monzó, Valentí Puig i Sergi Pàmies - que ho fan en català-, i Bernardo Atxaga - que ho fa en eusquera.

El primer conte del volum és el de Robert Saladrigas i duu per títol "Child Rodolfo". Al llarg del text (p. II-I7) hi trobem tres notes a peu de pàgina de la traductora, les tres diuen "Castilian in the original text". El conte és situat a Santillana del Mar, a Santander, i les paraules en qüestió són "churrasco", "la Montaña" (amb majúscula, és a dir la comarca d'aquest nom) $\mathrm{i}$ "hidalgo". El lector incaut queda un cop més una mica sorprès per les notes de la traductora ja que, atès que es tracta d'una antologia de contes espanyols, que l'acció transcorre a Santander, que per tant no sembla gaire exòtic ni injustificat que els personatges s'expressin en castellà, i que no s'ha fet cap indicació en sentit contrari, hom donava per suposat que tot el conte devia ser traduït del "Castilian". Només en arribar a la fi, al parèntesi que menciona el nom de la traductora aleshores se'ns indica: "Translated from the Catalan by Julie Flanagan" (p. I7).

El conte "Report" de Carme Riera duu una nota inicial a peu de pàgina de la traductora. "This story, like almost all of Carme Riera's work, was originaly written in Majorcan, the variation on Catalan spoken in the Balearic island of Majorca. Unfortunately the manuscript was lost and this English translation is, perforce, from a Castilian version the author prepared for the anthology Doce relatos de mujer (Alianza, 1982)." El relat té una nota de la traductora a un mot mallorquí i una a un mot espanyol. La traductora, Julie Flanagan, especifica al final, com ho havia especificat al conte de Saladrigas, la llengua de la qual ha traduït: "Translated from the Castilian". En aquest cas, doncs, és la traductora qui ens adverteix que habitualment Carme Riera escriu en català però que, de manera del tot excepcional, en aquesta ocasió la traducció ha estat feta a partir de la traducció castellana de l'original extraviat.

Els relats de Quim Monzó - "'Oof', he said"-, de Valentí Puig - "First Days" - i de Sergi Pàmies _ "Losing Face" - són traduits per Andrew Langdon-Davies. A cap dels tres no hi apareix cap mena de nota ni s'hi diu de quina llengua han estat traduïts.

Tampoc no hi ha cap indicació de llengua de procedència en el de Bernardo Atxaga — "The Torch" - traduit per Margaret Jull Costa.

En cap dels altres vint-i-tres contes del volum tampoc no hi ha cap indicació de la llengua de procedència. El lector, per tant, procedeix a pressuposar l'homogeneïtat de la llengua de partida en tots els relats, llevat del cas de Saladrigas i de l'excepció del conte de Carme Riera que ha acabat essent traduït del castellà.

Només a les pàgines 202-208, en la secció final del llibre "About the Authors" podem aleshores assabentar-nos que Atxaga "writes in Bas- 
que”, que Quim Monzó és "a Catalan writer" que ha estat traduït al castellà, igual com ho és Sergi Pàmies, o que Valentí Puig "writes in Majorcan" igual que Carme Riera, i que Robert Saladrigas ho fa "in Catalan" encara que l'obra de tots tres hagi estat "translated into Castilian".

La descurança d'aquest cas sembla obeir al cansament, a la desídia general i a una mena de prejudici ètico-lingüístic: "no paga la pena d'embolicar la troca mental del lector anglès amb les diferents llengües de l'Estat espanyol i més val vendre-li els contes traduits com un sol paquet comercial amb el reclam de l'Espanya almodovariana". Ho dic tot i reconèixer que la meva explicitació ideològica dels arguments d'altri - en aquest cas dels editors anglesos- és, també, clara i confessada, una explicitació ideològica per la meva part. M'hauria agradat veure explicitat l'origen lingüístic divers dels contes inclosos a l'antologia i penso sincerament que l'antologia hauria guanyat en claredat $i$ representació de la realitat literària espanyola.

Per a les qüestions traductores que aquí ens interessen, tant el relat de Monzó com els contes antologats per Masoliver semblen apuntar a una invisibilitat de l'autor traduït en tant que autor traduit. En el cas de dos sistemes juxtaposats de pes específic desigual, en el cas d'una diglòssia cultural, com és ara la del castellà i la del català, el camp editorial dóna lògicament predomini al sistema més fort: el castellà. Allò que és literatura catalana traduida desapareix com a tal i passa a ser, simplement, un element més, no diferenciat, no distint, perfectament digerit, de la "Spanish literature". Referint-se a la literatura irlandesa, Michael Cronin $^{12}$ ha escrit que "quan hom deixa d'indicar la diferència lingüística i la naturalesa del procés de traducció es crea una illusió de transparència i s'oculta el grau i la mena de transformació que implica el canvi - Cronin fa referència al gaèlic irlandès- d'una llengua celta a una llengua germànica". Jo diria que aquesta ocultació, quan es tracta de llengües que filològicament són molt més pròximes, encara resulta més inexcusable.

El text original ha deixat de semblar diferent, ha deixat de mostrarse com una alteritat, per a ser absorbit i identificat amb el corrent majoritari, predominant, de la llengua de poder: l'espanyol. S'han esborrat totes les diferències i només percebem allò que és igual. ${ }^{13} \mathrm{La}$

I2 CRONIN, Michael, "Altered States: Translation and Minority Languages", in Gambier, Yves (ed.), Orientations Européenes en Traductologie, Études sur le Texte et ses Transformations" vol. VIII, $\mathrm{n}^{\circ}$ 1, p. 93.

I3 "In Canada, the federal authorities tend to erase all differences between social groups, let's say Anglos and French, and this shows in translations where both groups are supposed to believe the original texts were written in their mother tongue. That's immoral. That's policics and translators must decide if they are willing to play the game. What really matters is that if you decide to erase the differences between people, you do it consciously", escriu el 3 del XII de 1997 a Translat Louise Brunette (Études françaises, Université Concordia). 
llengua colonitzada esdevé invisible no perquè sigui negada o sotmesa sinó perqué se li atorga l'estatus de la homogenéitat total, és idèntica a la llengua colonitzadora, ha estat plenament fagocitada. L'assimilisme del poder és tan gran que, de fet, sembla com si en primer lloc calgués perdonar-li que sempre s'oblidi del reconeixement públic de la diferència, mentre que, en segon lloc, cal agrair-li la seva deferència per haver igualat el servidor al seu senyor. ¿ $\mathrm{O}$ és que aquests autors catalans haurien arribat mai ha ser publicats, traduits, divulgats de no haver comptat amb aquest mecenatge esplèndid i magnànim de la traducció a la llengua dominant? I el que dic respecte a la relació castellà/català es multiplica per cent si ho apliquem a la relació de domini que manté l'anglès amb moltes altres llengües. Ser "traduï" a l'anglès sóvint és percebut - prou enganyosament - com el senyal d'haver deixat de ser escriptor en una llengua minoritària. El llibre traduit que circula en anglès ja és un "original", un original dins el mercat editorial internacionalitzat que podrà, si cal, retraduir-lo a partir de l'anglès, oblidant el text original de l'escriptura. Però, per bé que aquesta posició de "llengua pont" de l'anglès és innegable, cal ressaltar que la majoria de llibres "traduïts a l'anglès" pertanyen, de fet, a la categoria no del que és igual, ni del que és igual dins la diferència, sinó del que és segon, secundari. L'existència del llibre traduït només és important perquè és una traducció, ja que, com a original, continua sense existir. Heus aquí la paradoxa de l'assimilisme. Si de cas és l'original qui deriva virtuts del fet d'haver estat traduït i no pas la traducció anglesa pel fet d'apropiarse d'un original $\mathrm{X}$ valuós. ${ }^{14}$

En l'enfrontament de sistemes culturals de poder desigual hi ha una mena de pensament teleològic sibil-lí. Tant en el cas de la primacia del castellà sobre el català com en l'hegemonia mundial de l'anglès semblem escoltar una lliçó que ja existia en els antics poders colonials. ${ }^{15}$ La finalitat d'escriure en català és ser traduït i triomfar en el mercat espanyol, com la finalitat última d'escriure en qualsevol llengua $\mathrm{i}$ des de qualsevol racó del món és ser traduït a l'anglès i triomfar en aquest mercat mundial. La llengua dominant esdevé, per la seva pròpia natu-

14 Un intent prou interessant de trencar aquest mecanisme ês el projecte Young Internet Translators (tardor 2000), finançat per la unió Europea i participat per el British Council, l'associació neerlandesa d'escriptors, l'associació danesa de promoció de la lireratura i la Institució de les Lletres Catalanes entre d'altres. Aquest projecte inclou textos breus d'autors en aquestes llengües, en una pàgina d'internet, i les seves traduccions al castellà, anglès í francès, amb comentaris dels traductors. La visibilitat dels autors, de les llengües minoritàries i de la traducció mateixa volen aparèixer-hi en peu d'igualtat. El projecte yol subratllar la importància de la traducció com un sine qua non igualitari per a la difusió de qualsevol literatura.

is Vegeu el que diu a aquest respecte Niranjana, Tejaswini, History, poststructuralism and the colonial context. Siting Translation, U.C.P. 1992, p. to-11 de la introducció. 
ra, una imposició totpoderosa semblant a la que va exercir la religió en alguns sistemes colonials - la seva supremacia és un axioma i la seva raó indiscutible emana del seu poder, de la seva força, més que no pas de cap suposada virtut intrínseca. (I els recordo que la virtut intrínseca de qualsevol llengua que cregui innecessària la seva traducció és, des del punt de vista de la traducció mateixa, una negació d'aquest valor de la diferència, de la diversitat, del traductor com a pont entre cultures.)

Només des d'aquesta postura homegeneïtzadora resulta comprensible que es negui el valor de traduccions tan interessants i necessàries com les que es fan des de les llengües de més gran difusió a les llengües de difusió restringida. Les traduccions del castellà al català o al gallec, per exemple. Totes les traduccions del Quixot de què tenim noticia ${ }^{16}$ han estat fetes precisament per enfortir el sistema literari català, des del desig d'anostrament que, per necessitat, implica un reconeixement del valor del que és altre. L'argument de molts dels traductors catalans del Quixot ha estat que si l'obra de Cervantes representava la culminació de la llengua espanyola, la seva traducció catalana, per imperfecta que fos, hauria de representar també una culminació de les virtualitats del català en tant que llengua de cultura literâria. Traduir, en aquest cas, ha estat enriquir, nodrir, més que no pas fagocitar.

I si en aquesta pràctica de traducció del castellà al català hi ha res d'absurd, l'absurd de la situació no sol ser percebut en la seva dimensió exacta. Si acceptem que és prou lògic de retraduir el Quixot al neerlandès, al francès o a l'anglès cada $X$ anys, semblaria de necessitat que també el retraduíssim al català. Llevat que, naturalment, la posició dels sistemes de les dues llengües (castellà/català) no sigui comparable a la posició dels sistemes de les llengües castellà/francès o castellà/neerlandès. Per tant, de seguida ens adonem que la necessitat de la traducció no depèn pas tant de l'"essencialitat" de les obres a traduir com de la posició que aquestes obres ocupen en el seu camp literari i de la relació que aquest camp guarda amb camps similars dins d'altres llengües. Quan afirmem que no cal traduir el Quixot al català diem que, en l'actual correlació de forces entre les dues llengües, i mentre aquesta correlació no canvii, aquesta traducció no és necessària des d'un punt de vista comercial. Estem afirmant que el lector català també pot - la qual cosa no vol pas dir que "hagi de"- llegir l'original castellà amb un grau de coneixement suficient per poder prescindir de la traducció.

I ja poden pensar que una estructura lògica similar es troba a la base de la polèmica sobre el doblatge de les pellícules al cinema. ¿S'han de doblar més pel-lícules al català? Sens dubte aquesta és una mesura

16 Treball de recerca d'Imma Estany i Morros, "Les traducions del Quixot al català', F.T.I., UAB, juny 1998. 
que enfortirà el sistema cultural català, però la decisió d'adoptar i aplicar la mesura és evidentment una decisió política. El fet que s'arribin a traduir (a doblar o a subtitular) més pel-lícules al català està condicionat per aquesta opció ideològica. I, si ens remuntem a un pla més general, podem plantejar-nos aquestes preguntes de forma encara més abstracta. ¿S'han de projectar les pel-lícules en versió original ja que això sempre és una marca de la diferència? ¿I ho hem de fer encara que el noranta per cent de les marques diferencials de la indústria cinematogràfica corresponguin a una sola llengua dominant, monopolista? ¿Ho hem d'acceptar per la pura raó, perquè aquesta i no altra és la fatalitat del mercat cinematogràfic mundial? ¿O podem anar encara més lluny i argumentar que ja que l'anglès és la lingua franca del segle XxI podem deixar en versió original les pel-lícules en anglès - llengua que, en un grau o un altre tothom coneix - i doblar només les pel-lícules que són en francès, en alemany, en italià, en suec... de manera que col-laborarem a enfortir el sistema cultural dominant $i$ a afeblir les petites diferències de les llengües menys usades fins a anorrear-les? Em sembla que els exemples són prou clars perquè ens adonem que la traducció mai no és una activitat políticament innocent.

Quan a la primavera de 1998 el Centro Dramático Galego no va poder representar Valle-Inclán en gallec perquè els hereus de ValleInclán es van oposar a que fos traduït a aquesta llengua $\mathrm{i}$ aleshores es va considerar l'alternativa que l'obra es representés en espanyol, esclatà una gran polèmica. ${ }^{17}$ Allò que hi havia al darrere eren opinions contraposades sobre la funció de la traducció. En un cas es defensava la redundància de la traducció de Valle-Inclán al gallec: "traducir a Valle-Inclán al gallego (e interpretarlo) es innecesario más allá del experimento filológico; todos lo entienden allí en español, y seguramente en algunas de sus obras (...) con mayor acuidad que en otros territorios de España", deia un crític ben poc partidista en aquestes qüestions, com Miguel García Posada. De l'altra banda s'argumentava que tota traducció és, per necessitat, un enriquiment, que "quen se alporiza diante da posibilidade de facer a Valle en galego existindo o orixinal en español, está a negarlle aó galego o seu dereito como idioma a acoller no seu seo lingüístico unha obra universal escrita noutro idioma". En els casos més curiosos s'arribava a jerarquitzar les llengües a partir de les quals cal traduir "Sófocles o Goethe sí deben ser tradu-

17 Vegeu els articles: Hermida, José, "Don Ramón no habla gallego"; El País, 28 de març de 1998, p. G4; Garcí POSADA, Miguel, "El idioma de Valle-Inclăn", El Pais, dijous 2 d'abril de 1998, p. 32; RIVAS, Manuel, "Valle-Inlán, Galicia y la libertad amenazada", El Paí, 5 d'abril de 1998, p. I5; FERNAN-VELlo, Miguel A., "Sobre a traducción", A Nosa Terra, 8 d'abril de 1998, p. 21. Dec una part d'aquesta informació a la Sra. Yolanda Velasco Ríos de la F. de Traducció de Vigo, que treballa sobre aquest tema. 
cidos al gallego, porque el público mayoritario no conoce sus idiomas originales, pero Valle-Inclán es un caso aparte, una mezcla de gallego y castellano que resultaría absurdo traducir" (Xesus Alonso Montero). Fet i fet, totes aquestes opinions tenen la seva part de raó pràctica. Però examinades des d'un punt de vista teòric, sorprèn que no s'expressi clarament, en parlar de la traducció, que allò que hi té un pes més especific és la correlació de forces entre la llengua de partida i la llengua d'arribada. En el cas de la traducció del castellà al gallec sembla que es reafermi que el gallec és una mena de patois que no paga la pena d'enfortir culturalment i que aquesta situació de desigualtat va en favor de la llengua dominant però no de la llengua vampiritzada. ¿Gosaríem aplicar el mateix argument a l'inrevés i demanar que tota la literatura gallega fos sempre present en l'àmbit lingüistic de l'espanyol sense traduir perquè atès el mateix quid pro quo els lectors o espectadors espanyols també haurien de ser capaços de comprendre el gallec? ¿Oi que de seguida veuen l'asimetria d'aquesta mena d'argumentació? En una direcció funciona, però en la direcció inversa no.

Insisteixo en aquestes qüestions perquè considero que posen en primer terme la rellevància de la traducció com a acte fonamental de la comunicació i com a acte d'enfortiment dels sistemes culturals. L'existència d'un teatre gallec està en funció no sols de la capacitat de traduir al gallec sinó de la voluntat de fer-ho. I és pertinent recordar que tenim molts exemples històrics d'aquesta voluntat política de crear elements que permetin la subsistència ofins i tot la creació de rel de sistemes culturals. L'existència d'una literatura hebrea moderna depèn de la voluntat d'un Estat que implantà l'oficialitat d'una llengua que tenia uns usos ben restringits en tots els àmbits de la vida social. En el món altament globalitzat de principis del segle XXI, la traducció per ella sola no pot fer valer el seu protagonisme si no va acompanyada d'aquesta consciència de la seva relació amb els sistemes que detenten el poder i la seva manifestació a través de determinada activitat política. I sempre que trobem en joc la supervivència d'un determinat sistema cultural aquesta relació serà encara més evident.

Crec que, més enllà de les nocions de relació lingüística, hem de començar a introduir en els estudis sobre la traducció aquestes perspectives sociològiques que determinen el valor d'aquelles relacions. I, en primer lloc, la nóció d'asimetria direccional en la traducció. ${ }^{18}$ Els exemples de traduccions del Quixot al català a què m'he referit abans, - les traduccions de Valle-Inclán al gallec, tenien uns objectius, una intencionalitat, del tot diferent a les motivacions que poden existir per

18 Faig servir l'expressió tal i com l'empra CRONIN, Michael a "Altered States: Translation and Minority Languages", in GAMBIER, Yves (ed.), Orientations Européenes en Traductologie, Études sur le Texte et ses Transformations" vol. VIII, nº $1, \mathrm{p} .85-103$. 
traduir autors gallecs o catalans al castellà, tal i com exemplificava el conte de Quim Monzó o l'antologia a l'anglès de Masoliver Ródenas. Postular una relació igualitària entre el text de partida i el text d'arribada, com si aquests textos existissin en un buit absolut, és tornar a caure en els paranys ja antics de la lingüística comparada. El valor social i cultural de la traducció -és a dir, el seu valor de canvi efectiu en la vida quotidiana - està en funció del seu valor polític, és a dir, de la capacitat d'acció que la traducció pugui tenir, en tant que valor intel-lectual, d'intercanvi o de motor econòmic, de prestigi, dins un sistema cultural concret.

A ningú dels presents no els costarà d'imaginar el valor "decoratiu" d'una traducció del castellà al català. És el valor que habitualment els atorguem quan ens assabentem que existeixen traduccions de Crònica d'una mort anunciada o de La familia de Pascual Duarte. ${ }^{\text {I9 }}$ Però és curiós remarcar que, des de la cultura receptora i des de la cultura de partida, aquestes obres són rebudes amb qualificacions diferents, segons afectin el sistema que les valora. $O$ pel fet de ser del tot "innecessàries" se les judica com una mena de bajanada, d'"experiment filològic" de valor dubtós, o precisament per ser innecessàries se les judica com una fita més de la gran difusió de l'original que ha arribat - segons semblen dir-nos- fins i tot més enllà d'on calia esperar que arribés.

Davant d'aquesta desigualtat de la posició social i política que ocupen les llengües és natural que algú pugui arribar a proposar una negativa total a ser traduit. És l'extrem que, contrari a l'assimilisme, podem denominar de "resistència a la traducció". Douglas Robinson ho descriu en un dels capítols dels seu llibre Translation and Taboo. ${ }^{20} \mathrm{Hi}$ explica com intenta que un amic seu que treballa per al Navajo Community College de New Mexico l'introdueixi al món de la poesia dels escriptors navajos i l'ajudi a traduir-ne algun poema. El seu amic, altres estudiosos de la llengua navajo, $i$ alumnes que la tenen com a primera llengua, tots es neguen a donar-li'n referències o a traduir-li poemes. Ha de ser amb l'ajut d'un diccionari que l'autor arribi a destriar el sentit d'alguns poemes i a fer-ne una petita selecció pel seu compte i quan busca una professora de poesia en navajo que li confirmi el sentit del poema triat, aquesta li respon: "No puc ajudar-lo amb els poemes de Rex Lee". "Ho sento. Podria ajudar-lo, però no ho faré. En Rex Lee no vol aquests poemes en anglès. Diu que si els hagués volgut en

I9 De la primera n'existeix traducció catalana d'Avel-lí Artís Gener a la col·lecció Plec de Setze, de l'editorial Grijalbo, Barcelona, 1982. De la segona, se'n va fer una traducció catalana a cura d'en Miquel M. Serra Pastor, amb próleg de Li. Villalonga, publicada a Ciutat de Mallorca per Atlante el 1956, en una edició de 450 exemplars.

20 Róminson, Douglas, Translation and Taboo, Illinois, Northern Illinois University Press 1995, p.171-176. 
anglès ja els hi hauria escrit directament. Que no han estat escrits perquè els blancs els explotin. I jo no penso trair la seva confiança". $\mathrm{I}$, a continuació, la professora explica que en navajo són uns poemes molt bonics i que ella els estudia i comenta a classe de literatura navaja amb els alumnes, que Rex Lee és un autor extraordinari a l'hora d'emprar els recursos de la llengua però que, en la traducció, "es perdria massa". Ella mateixa prepara un llibre de comentari per a la Cambridge University Press, però és íntegrament escrit en navajo. El seu grau màxim de tolerància és fer-ne un resum d'una línia, "fer-ne un resum més ampli, afegeix, equivaldria a trair l'obra en navajo, i els lectors anglesos en tindrien una idea equivocada".

Aquesta resistència a la traducció és clarament una resistència a l'anorreament. Si allò que es diu en navajo també pot ser igualment dit en anglès ja no caldrà dir-ho en navajo. Forçar el poema de Rex Lee a sortir de la seva llengua és expulsar-lo, paradoxalment, de l’única "reserva" que li queda, condemnar-lo a la diàspora. En aquesta situació la diferència entre els sistemes político-culturals del navajo i de l'anglès americà és tan abismal que la traducció és un genocidi. Demanar d'un sistema cultural molt feble que sigui, a més a més, permeable és demanar-li que accepti dissoldre's del tot, aigualir-se completament. Qui vulgui llegir literatura en navajo, sembla dir-nos l'exemple de Douglas Robinson, que s'incorpori a la cultura dels navajo, que esdevingui navajo. En lloc de traduir DEL navajo, traduïm-nos AL navajo. Que sigui el públic potencial qui sigui "navajitzat" i no les obres "anglitzades".

Sens dubte aquest és un cas extrem, però com tots els casos extrems, molt instructiu per la seva demagògia pedagògica. Aquesta resistència absoluta a la traducció segurament és utòpica però pot servir per fer-nos veure que allò que des d'un punt de vista polític, i per tant, públic, cal reivindicar - i amb això acabo i tanco el cercle de l'exposició-, és que tota traducció faci visible la marca de la diferència en tant que reconeixement de l'alteritat. Que els escriptors en llengua catalana no siguin simplement presentats com si fossin "Spanish writers" sense més, esbandint la marca de la seva llengua i de la seva cultura. I que aquesta marca serveixi perquè els lectors puguin sentir curiositat envers la cultura catalana, envers la llengua. Que la traducció serveixi perquè aquesta diferència $\mathrm{i}$ aquesta alteritat de què parla el col-loqui que avui ens aplega a Bloomington siguin respectades. Que la possibilitat de "viure en català" que demanava la carta del lector del diari Avui no sigui incompatible amb la traducció d'aquesta vida al castellà i que la coexistència de totes dues sigui una acceptació plausible i democràtica, enriquidora, de la convivència d'allò que és diferent. Si com a escriptor i traductor hi puc contribuir en res, ja saben que aquest és un dels meus interessos. Si, a més, en les meves actuals funcions de 
Director de la Institució de les Lletres Catalanes, que té entre les seves funcions la difusió de la literatura catalana, puc ajudar-los en aquesta tasca, sàpiguen també que aquest reconeixement del que som a través de la traducció és una de les nostres prioritats.

Moltes gràcies.

[Primera versió: Barcelona / Harbor Springs, agost 1998

Revisat a Bloomington, 2 de març de 2000] 